\title{
Communication
}

\section{Direct growth of highly strained Pt islands on branched Ni nanoparticles for improved hydrogen evolution reaction activity}

Ali Alinezhad, Lucy Gloag, Tania M. Benedetti, Soshan Cheong, Richard F. Webster, Martin Roelsgaard, Bo B. Iversen, Wolfgang Schuhmann, John Justin Gooding, and Richard D. Tilley J. Am. Chem. Soc., Just Accepted Manuscript • DOI: 10.1021/jacs.9b07659 • Publication Date (Web): 03 Oct 2019

Downloaded from pubs.acs.org on October 7, 2019

\section{Just Accepted}

"Just Accepted" manuscripts have been peer-reviewed and accepted for publication. They are posted online prior to technical editing, formatting for publication and author proofing. The American Chemical Society provides "Just Accepted" as a service to the research community to expedite the dissemination of scientific material as soon as possible after acceptance. "Just Accepted" manuscripts appear in full in PDF format accompanied by an HTML abstract. "Just Accepted" manuscripts have been fully peer reviewed, but should not be considered the official version of record. They are citable by the Digital Object Identifier (DOI®). "Just Accepted" is an optional service offered to authors. Therefore, the "Just Accepted" Web site may not include all articles that will be published in the journal. After a manuscript is technically edited and formatted, it will be removed from the "Just Accepted" Web site and published as an ASAP article. Note that technical editing may introduce minor changes to the manuscript text and/or graphics which could affect content, and all legal disclaimers and ethical guidelines that apply to the journal pertain. ACS cannot be held responsible for errors or consequences arising from the use of information contained in these "Just Accepted" manuscripts. 


\title{
Direct growth of highly strained Pt islands on branched Ni nanoparticles for improved hydrogen evolution reaction activity
}

\author{
Ali Alinezhad, ${ }^{\dagger}$ Lucy Gloag, ${ }^{\dagger}$ Tania M. Benedetti, ${ }^{\dagger}$ Soshan Cheong, ${ }^{\dagger}$ Richard F. Webster,,${ }^{\dagger}$ Martin

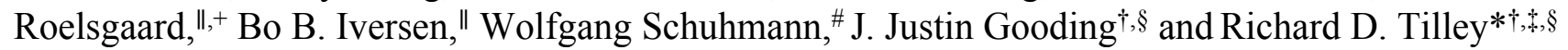 \\ † School of Chemistry, The University of New South Wales, Sydney, New South Wales 2052, Australia \\ ‡ Mark Wainwright Analytical Centre, The University of New South Wales, Sydney, New South Wales 2052, Australia \\ \| Center for Materials Crystallography, Department of Chemistry and iNANO, Aarhus University, Langelandsgade 140, \\ DK-8000 Aarhus C, Denmark \\ + PETRA III, Deutsches-Elektronen Synchrotron (DESY), Notkestr. 85, D-22607 Hamburg, Germany \\ \# Analytical Chemistry - Center for Electrochemical Sciences (CES), Faculty of Chemistry and Biochemistry, Ruhr \\ University Bochum, Universitätsstr. 150, D-44780 Bochum, Germany
} $\S$ Australian Centre for NanoMedicine, The University of New South Wales, Sydney, New South Wales 2052, Australia

\section{Supporting Information}

\begin{abstract}
The direct growth of $\mathrm{Pt}$ islands on lattice mismatched $\mathrm{Ni}$ nanoparticles is a major synthetic challenge and a promising strategy to create highly strained Pt atoms for electrocatalysis. By using very mild reaction conditions, $\mathrm{Pt}$ islands with tunable strain were formed directly on $\mathrm{Ni}$ branched particles. The highly strained $1.9 \mathrm{~nm}$ Pt-island on branched Ni nanoparticles exhibited high specific activity and the highest mass activity for HER in $\mathrm{pH} 13$ electrolyte. These results show the ability to synthetically tune the size of the $\mathrm{Pt}$ islands to control the strain to give higher HER activity.
\end{abstract}

Strained $\mathrm{Pt}$ on the surface of a $\mathrm{Ni}$ core is a promising nanoparticle structure for highly active hydrogen evolution (HER) and oxygen reduction (ORR) electrocatalysis. ${ }^{1-7}$ The most intuitive way to synthesize these target nanoparticles is by a 'bottom-up' approach involving the direct growth of Pt on $\mathrm{Ni}$ nanoparticles. Growth of $\mathrm{Pt}$ on $\mathrm{Ni}$ nanoparticles is synthetically challenging due to the large $\mathrm{Pt}-\mathrm{Ni}$ lattice mismatch $(\sim 10 \%)$ and has yet to be achieved. More intricate 'top-down' approaches have been used to access de-alloyed Pt-Ni nanoparticle catalysts with excellent specific and mass activity for the ORR, ${ }^{5,8-10}$ however, a 'bottom-up' synthesis for strained Pt on Ni nanoparticles is still needed.

HER in alkaline media is key for hydrogen production in the water splitting process. ${ }^{11-14}$ HER nanoparticle catalysts need 1) neighboring $\mathrm{Pt}$ and $\mathrm{Ni}$ atoms at the nanoparticle surface: $\mathrm{Ni}$ atoms accelerate the dissociation of water by adsorbing $\mathrm{OH}^{*}$, promoting the recombination of the $\mathrm{H}^{*}$ intermediates to form $\mathrm{H}_{2}$ at the $\mathrm{Pt}$ sites; ${ }^{11,12,14-16}$ 2) strained $\mathrm{Pt}$ to modify the hydrogen binding energy, ${ }^{3}$ enabling effective electron transfer and easy desorption of $\mathrm{H}_{2}$ giving increased HER activity. ${ }^{17,18}$ Thus, having strained $\mathrm{Pt}$ on a Ni core enhances the two most important HER steps.
Additionally, having Pt located at the surface and available for catalysis is desirable rather than in the nanoparticle core to improve the mass activity and lower the required mass of expensive Pt.

To date, Pt has only been deposited onto highly lattice mismatched metal cores by using an intermediate layer of a third metal between the Pt and the metal core. This third metal decreases the lattice difference and reduces the $\mathrm{Pt}$ strain. ${ }^{19-21}$ If Pt can be directly grown onto $\mathrm{Ni}$, the Pt should exhibit more compressive strain. Simultaneously, the number of adjacent Pt-Ni atoms that are important for HER electrocatalysis would substantially increase. ${ }^{22}$ Recently, other highly lattice mismatched core-shell nanoparticles have been synthesized by slow reduction and deposition of the secondary metal onto a core. ${ }^{23,24}$ This strategy offers an opportunity to directly grow Pt onto $\mathrm{Ni}$.

In this work, a slow reduction approach was used to directly grow Pt islands on $\mathrm{Ni}$ nanoparticles by employing very mild reaction conditions which formed Pt monomers at low concentrations and prevented heterogeneous nucleation of $\mathrm{Pt}$ atoms. ${ }^{25,26}$ The small $\mathrm{Pt}$ islands on branched $\mathrm{Ni}$ nanoparticles showed tunable strain and high specific and mass activity for HER in alkaline electrolyte.

Pt islands were directly grown on branched $\mathrm{Ni}$ nanoparticles by slow growth as illustrated the scheme Figure 1a. In a synthesis, $\mathrm{Pt}(\mathrm{acac})_{2}$ dissolved in toluene was added to a solution of branched Ni nanoparticles ${ }^{27}$ with the surfactants hexadecylamine (HDA) and trioctylphosphine (TOP) in a Fischer-Porter bottle at $40{ }^{\circ} \mathrm{C}$ and 3 bar $\mathrm{H}_{2}$ pressure (see SI for experimental details). After $48 \mathrm{~h}$, monodispersed $1.9 \pm 0.5 \mathrm{~nm}$ Pt islands were formed (Figures 1b-c, S1) and distributed over the surface of the branched Ni nanoparticles to give a high number of adjacent $\mathrm{Pt}-\mathrm{Ni}$ atomic sites. Scanning 
a)

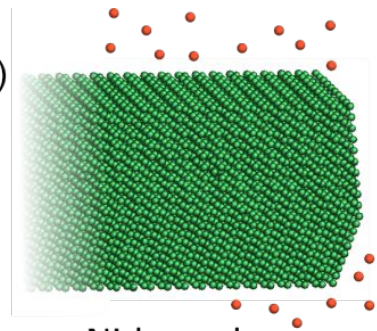

$\mathrm{Ni}$ branches

b)

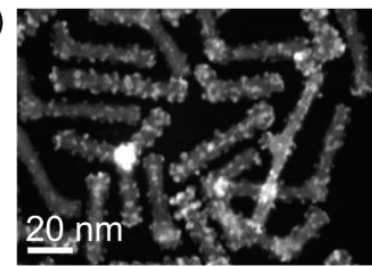

f)

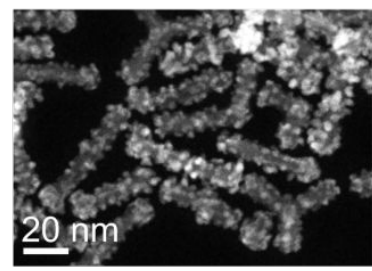

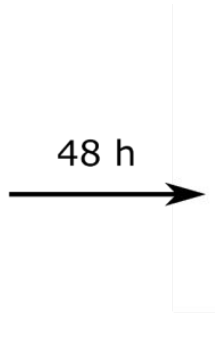

c)
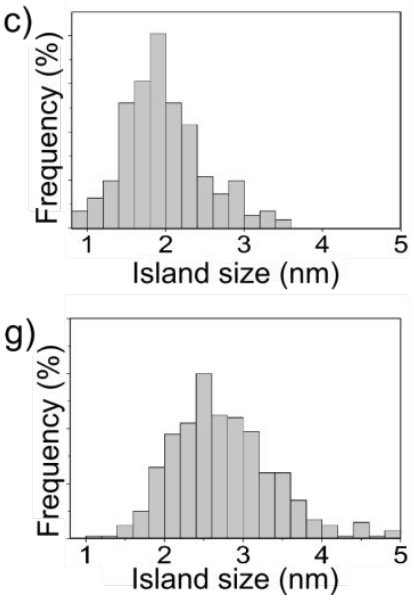

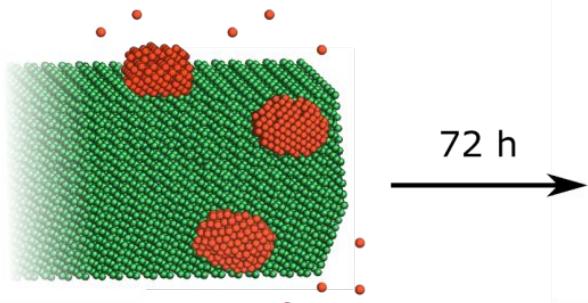

$1.9 \mathrm{~nm}$ Pt islands

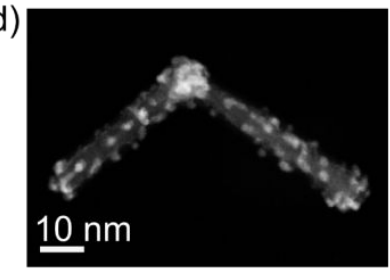

e) Pt



$2.7 \mathrm{~nm}$ Pt islands
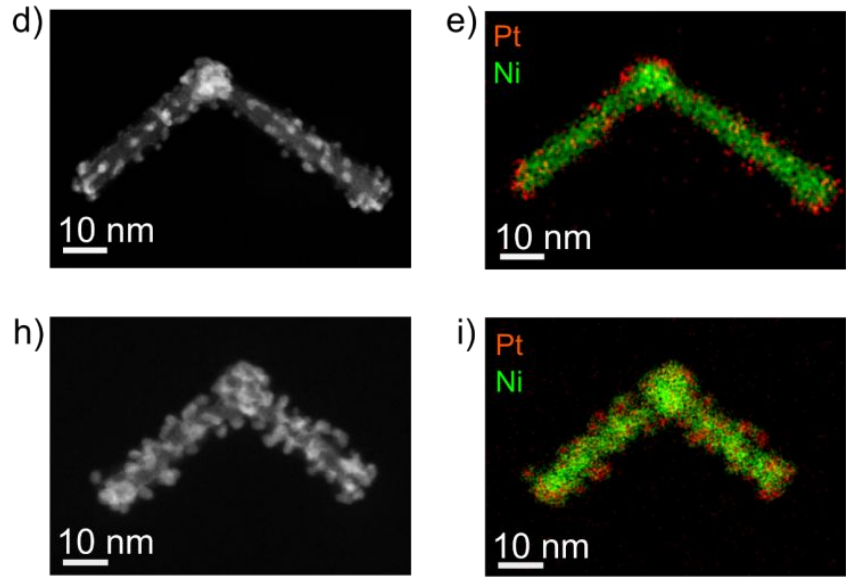

Figure 1. a) Scheme illustrating growth of Pt atoms (red) directly on a Ni branch (green). b) TEM image of the Ni-branched Ptislands nanoparticles after $48 \mathrm{~h}$ (1.9 nm Pt-island) c) Pt island size distribution. d) HAADF-STEM image of a Ni-branched 1.9 Ptisland nanoparticle, e) STEM-EDX map showing Pt (red) islands on Ni (green) nanoparticle. f) TEM image and g) Pt island size distribution after $72 \mathrm{~h}$ (Ni-branched $2.7 \mathrm{~nm}$ Pt-island), h) HAADF-STEM image of a Ni-branched $2.7 \mathrm{~nm}$ Pt-island, i) STEM-EDX map with Pt (red) and Ni (green).

transmission electron microscopy energy-dispersive X-ray spectroscopy (STEM-EDX) mapping shows that the islands are Pt metal with no alloying (Figures 1d,e). The nanostructures having an $11 \% \mathrm{Pt}$ atomic loading.

This slow reduction method enables fine control over the size of the Pt islands with the steady addition of Pt over time. Larger, $2.7 \pm 0.7 \mathrm{~nm}$ Pt islands were formed by increasing the reaction time to $72 \mathrm{~h}$ (Figure 1f). The Ni-branched Pt-island nanoparticles have an overall $21 \%$ atomic Pt content, observable in STEM-EDX imaging and mapping (Figures $1 \mathrm{~h}-\mathrm{i}$ ).

In our system the reaction of Pt precursor is slow, with unreacted precursor still remaining in the reaction after $72 \mathrm{~h}$ (Figure S2). In comparison, typical Pt coated nanoparticles are formed with the Pt precursor consumed much more rapidly. ${ }^{28}$ The concentration of $\mathrm{Ni}$ in the supernatant remains at near zero, indicating that $\mathrm{Pt}$ atoms are deposited without any observable galvanic replacement. This is due to the reaction occurring in an organic non-polar solvent. ${ }^{23-25}$

The Ni-branched Pt-island nanoparticles show a high and similar degree of control over island size compared to $\mathrm{Pt}$ islands on films, ${ }^{29}$ foams, ${ }^{30}$ nanosheets ${ }^{31-33}$ and more closely lattice matched metals like $\mathrm{Au} .^{34}$

HER activity of the Ni-branched Pt-island nanoparticles supported on carbon Vulcan and deposited on a glassy carbon surface was studied in $0.1 \mathrm{~mol} \mathrm{~L}^{-1} \mathrm{KOH}$ as the electrolyte solution. The specific activity was obtained by normalizing the capacitance corrected currents from the linear sweep voltammogram with the electrochemical surface area (ECSA) with the working electrode rotating at $1600 \mathrm{rpm}$. The ECSA of the active $\mathrm{Pt}$ was obtained by $\mathrm{H}_{\mathrm{UPD}}$, with no observed contribution from Ni (Figure S3).
The Ni-branched $1.9 \mathrm{~nm}$ Pt-island nanoparticles achieve a specific activity of $14.7 \pm 0.1 \mathrm{~mA} \mathrm{~cm}{ }^{2}$ at a potential of $70 \mathrm{mV}$ (RHE), which is 7.5 times higher than that obtained with commercial Pt/C nanoparticles of a similar size of $1.6 \pm 0.5 \mathrm{~nm}$ (Figure S4) under the same conditions. At the same potential, the Ni-branched $2.7 \mathrm{~nm}$ Pt-island nanoparticles achieve a specific activity of $6.4 \pm 0.7 \mathrm{~mA} \mathrm{~cm}_{\mathrm{Pt}}^{-2}$ (Figure 2a), which is only $43 \%$ of that achieved by the $1.9 \mathrm{~nm}$ Pt islands but still 3.3 times higher than that of commercial Pt/C.

The high number of Pt atoms accessible for electrocatalysis on the surface of the Ni-branched Pt-island nanoparticles also contribute to a mass activity that is 9.6 times higher for 1.9 $\mathrm{nm}$ island with a mass activity of $7.7 \pm 0.6 \mathrm{~mA} \mu \mathrm{g}_{\mathrm{Pt}}^{-1}$ and 3.0 times higher for $2.7 \mathrm{~nm}$ islands, at $2.3 \pm 0.1 \mathrm{~mA} \mu \mathrm{g}_{\mathrm{Pt}}^{-1}$, compared to $0.8 \pm 0.1 \mu \mathrm{g}_{\mathrm{Pt}}^{-1}$ for commercial Pt (Figure 2b). This leads to a mass activity for HER among the highest reported to date and the record activity in the less corrosive pH 13 electrolyte (Table S1)..$^{35,36}$

The stability for HER of Ni-branched $1.9 \mathrm{~nm}$ Pt-islands is considerably higher than that of the $2.7 \mathrm{~nm}$ island nanoparticles and commercial Pt. After $10 \mathrm{~h}$ of an applied current density at $10 \mathrm{~mA} \mathrm{~cm}^{-2}$, the Ni-branched $1.9 \mathrm{~nm} \mathrm{Pt}$ island nanoparticles show a potential shift of only $59 \mathrm{mV}$, which is approximately 3 times lower than both the $2.7 \mathrm{~nm} \mathrm{Pt}$ island nanoparticles $(166 \mathrm{mV})$ and commercial Pt $(165 \mathrm{mV})$ (Figure S5) and comparable to similar Pt based catalysts for HER. $^{33,36,37}$ Imaging of the same area of the TEM grid before and after 10,000 HER cycles showed the Ni-branched $1.9 \mathrm{~nm}$ Pt-island nanoparticles were not noticeably changed (Figure S6). Indicating the structural stability of the nanoparticles during HER catalysis. 

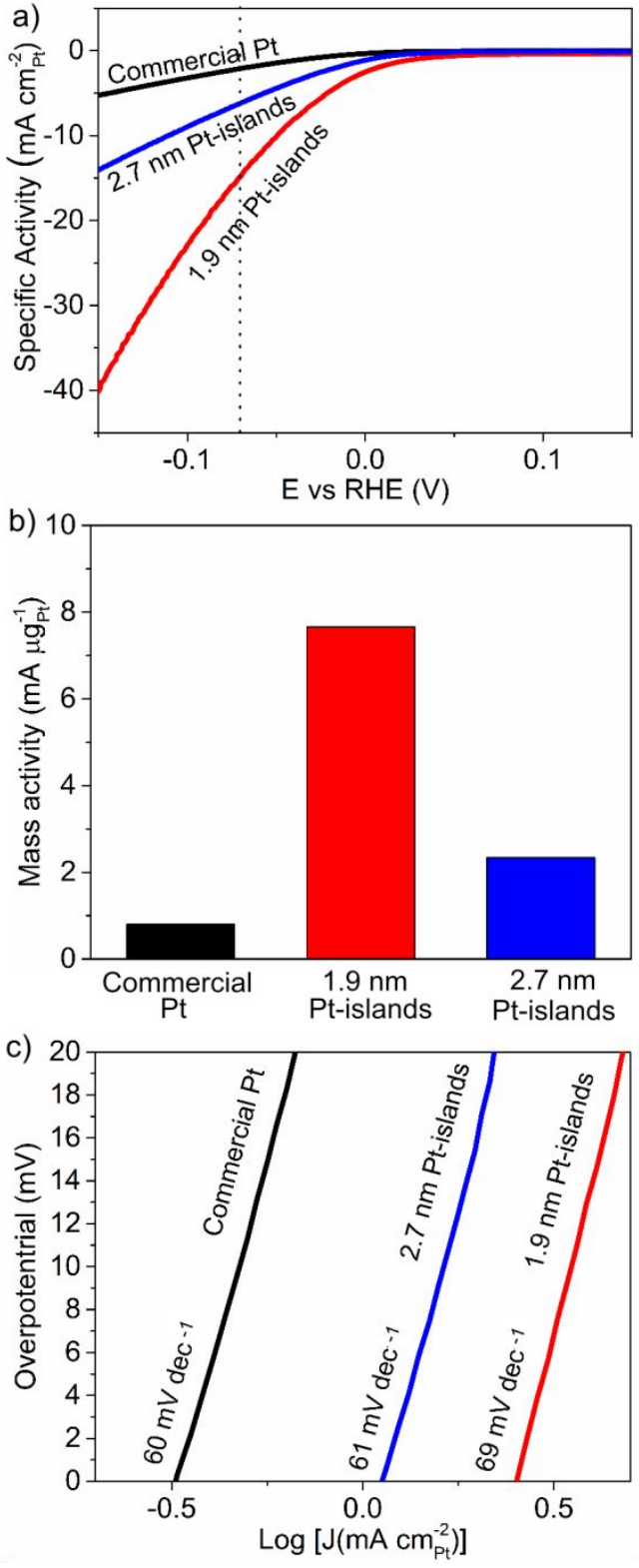

Figure 2. a) HER polarization curves for Ni-branched Ptislands nanoparticles and commercial Pt catalysts. Linear sweep voltammetry in $0.1 \mathrm{~mol} \mathrm{~L}^{-1} \mathrm{KOH}$ at a scan rate of $10 \mathrm{mV}$ $\mathrm{s}^{-1}$. The dotted line intersects the curves at $-70 \mathrm{mV}$. b) Mass activity of Ni-branched Pt-islands and commercial Pt measured at $70 \mathrm{mV}$ overpotential. c) Tafel plots obtained from the polarization curves in a).

HER follows the same reaction pathway on Ni-branched Ptisland and commercial Pt nanoparticles, with water dissociation (Volmer step) as the rate determining step, ${ }^{12,38,39}$ as shown by the similar Tafel slopes (Figure 2c). The similar Tafel slopes indicate that it is unlikely that the increased activity of the Ni-branched Pt-island nanoparticle is caused by a change in the rate-determining step. ${ }^{40}$

Aberration-corrected high-resolution TEM (HRTEM) of Nibranched $1.9 \mathrm{~nm}$ Pt-island nanoparticles are shown in Figures $3 \mathrm{a}$ and S7. The presence of strain and crystal defects is indicated by the streaks in the FFT of the image of the island (Figure 3b). HRTEM revealed that the $\mathrm{Pt}$ atoms grow epitaxially on the $\mathrm{Ni}$ atoms and that both metals adopt both
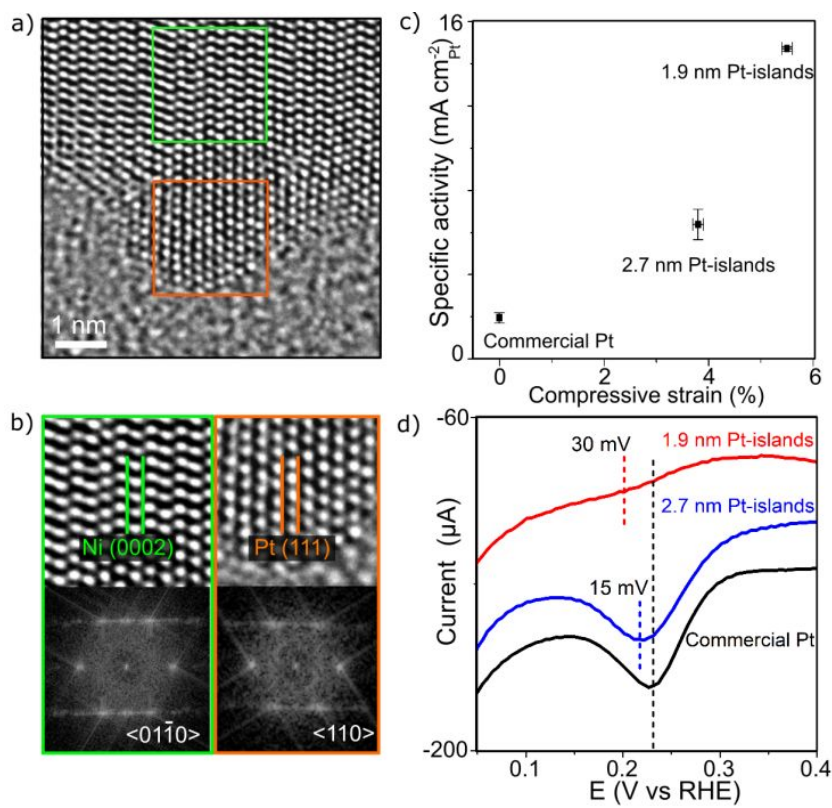

Figure 3. a) HRTEM image of a Pt island on Ni-branched 1.9 $\mathrm{nm}$ Pt-islands nanoparticle. b) The atomic arrangement of $\mathrm{Ni}$ atoms (green box) and Pt atoms in the island (red box) in a), and their corresponding FFTs. c) Strain-activity trend, showing the activity enhancement with increasing the stain. d) Hydrogen adsorption region of the cyclic voltammetry (CV) showing the negative shift in the position of the peak caused by increasing strain.

$f c c$ and $h c p$ crystal structures (Figures $3 \mathrm{~b}$, S8). ${ }^{27}$ The $1.9 \mathrm{~nm}$ Pt-islands have a Pt(111) lattice spacing of $2.14 \pm 0.04 \AA$ (Figures S9a, S10-12), which is a $\sim 5.5 \pm 0.1 \%$ lattice contraction compared to bulk Pt of $2.26 \AA$ (Eq. S2). ${ }^{5,41}$ The 2.7 nm Pt-islands have a Pt(111) lattice spacing of $2.18 \pm 0.05 \AA$ (Figure S9b) and a smaller compressive strain of $\sim 3.8 \pm 0.1 \%$, illustrating that the strain can be tuned by controlling the island size. The lattice spacing were calculated from HRTEM intensity line profiles of over 50 different islands across 5-12 $\operatorname{Pt}(111)$ lattice planes.

The Pt island lattice contraction was characterized by highenergy X-ray total scattering and pair distribution function (PDF) analysis. The PDF of the Ni-branched $1.9 \mathrm{~nm}$ Pt-island nanoparticles was fitted to $f c c-\mathrm{Pt}, h c p-\mathrm{Pt}, f c c-\mathrm{Ni}$ and $h c p-\mathrm{Ni}$ with an agreement factor $\left(R_{w}\right)$ of $12.3 \%$ (Figure S11, Table S2). PDF analysis showed Pt nanoparticle sizes of $\sim 2.0 \mathrm{~nm}$, in good agreement with the TEM observations. The $f c c-\mathrm{Pt}$ phase is strained with first nearest neighbor distance of $2.75 \AA$, and the $h c p$-Pt phase is highly disordered with a first nearest neighbor distance of $2.59 \AA$ A. The atomic weighted average PtPt bond distance was calculated to be $2.64 \AA$, which is a $\sim 5 \%$ contraction relative to bulk Pt and matches the $\sim 5.5 \%$ strain calculated from HRTEM. The Pt lattice contraction on the Nibranched Pt-island nanoparticles is similar to other highly strained Pt catalysts that achieve the highest specific activities for the ORR. $8,9,42,43$

The $\sim 1.4$ times increase in the compressive strain of the 1.9 $\mathrm{nm}$ Pt-islands compared to the $2.7 \mathrm{~nm}$ Pt-islands results in 2.3 times increase in the specific activity from $6.4 \mathrm{~mA} \mathrm{~cm}_{\mathrm{Pt}}^{-2}$ to $14.7 \mathrm{~mA} \mathrm{~cm}_{\mathrm{Pt}}^{-2}$ (Figure 3c). We expect the under-coordination of surface atoms also plays a role in the increase in specific activity as island size is decreased. ${ }^{28,44}$ Previously, such correlation between strain in nanoparticles and specific activity has been reported for the ORR. ${ }^{1,3,4,5,45,46}$ Our results 
show that synthetically modulating the Pt lattice-strain can improve and tune HER activity.

The impact of strain on $\mathrm{H}$-adsorption/desorption is observed by the differences in the position of current peaks corresponding to the $\mathrm{H}_{\mathrm{UPD}}$ adsorption in the CVs (Figures $3 \mathrm{~d}$, S12). For Ni-branched $1.9 \mathrm{~nm}$ Pt-islands, the peak corresponding to $\mathrm{H}_{\mathrm{UPD}}$ adsorption shifted by $30 \mathrm{mV}$ to more negative potentials compared to the commercial Pt; while for the $2.7 \mathrm{~nm}$ Pt-islands the potential shift is $15 \mathrm{mV}$. These negative potential shifts indicate a weaker hydrogen binding energy for $\mathrm{Ni}$-branched Pt-islands nanoparticles compared to commercial $\mathrm{Pt}, 3,47,48$ which enables faster desorption of $\mathrm{H}_{2}$ to give increased HER turnover during electrocatalysis (see Figure S15 and Table S3). ${ }^{6,49}$

In conclusion, the slow reduction solution synthesis enables the large lattice mismatch between $\mathrm{Ni}$ and $\mathrm{Pt}$ to be overcome to achieve the direct growth of Pt atoms on Ni nanoparticles for the first time to form strained $\mathrm{Ni}$-branched Pt-island nanoparticles. This enables the formation of highly strained $\mathrm{Pt}$ islands with both $\mathrm{Pt}$ and $\mathrm{Ni}$ atoms at the nanoparticle surface. The ability to synthetically tune the size of the Pt islands allows the strain to be controlled leading to the highest mass activity for HER at $\mathrm{pH} 13$. This slow reduction approach can be transferred to other systems with large lattice differences, thus providing the basis to obtain nanoparticle structures with strain for high performance catalysts.

\section{ASSOCIATED CONTENT}

\section{Supporting Information}

The Supporting Information is available free of charge on the ACS Publications website. Experimental details, additional characterization and calculations (PDF)

\section{AUTHOR INFORMATION}

\section{Corresponding Author \\ *r.tilley@unsw.edu.au}

\section{Notes}

The authors declare no competing financial interests.

\section{Acknowledgements}

This research was financially supported by the Australian Research Council of Centre of Excellence in Convergent BioNano Science and Technology (CE140100036), the ARC Australian Laureate Fellowship (FL150100060), the Discovery Project (DP190102659) and Center for Materials Crystallography, a Danish National Research Foundation Centre of Excellence (DNRF93). This work used the facilities supported by Microscopy Australia at the Electron Microscope Unit in the Mark Wainwright Analytical Centre at UNSW and at the Centre for Microscopy \& Microanalysis at the University of Sydney. W.S. is grateful for financial support from the Deutsche Forschungsgemeinschaft (DFG) under Germany's Excellence Strategy - EXC-2033 - 390677874. We acknowledge DESY (Hamburg, Germany), a member of the Helmholtz Association (HGF), for the beamtime at Beamline P21.1 at PETRA III and thank Martin von Zimmermann, Oleh Ivashko and Ann-Christin Dippel for support.

\section{REFERENCES} Wadayama, T. Oxygen Reduction Reaction Activity for
Strain-Controlled Pt-Based Model Alloy Catalysts: Surface Strains and Direct Electronic Effects Induced by Alloying Elements. ACS Catal. 2016, 6 (8), 5285-5289.

(2) Chattot, R.; Asset, T.; Bordet, P.; Drnec, J.; Dubau, L.; Maillard F. Beyond Strain and Ligand Effects: Microstrain-Induced Enhancement of the Oxygen Reduction Reaction Kinetics on Various PtNi/C Nanostructures. ACS Catal. 2017, 7 (1), 398408.

(3) Wang, X.; Zhu, Y.; Vasileff, A.; Jiao, Y.; Chen, S.; Song, L. Zheng, B.; Zheng, Y.; Qiao, S.-Z. Strain Effect in Bimetallic Electrocatalysts in the Hydrogen Evolution Reaction. ACS Energy Lett. 2018, 3 (5), 1198-1204.

4) Zhang, S.; Zhang, X.; Jiang, G.; Zhu, H.; Guo, S.; Su, D.; Lu, G.; Sun, S. Tuning Nanoparticle Structure and Surface Strain for Catalysis Optimization. J. Am. Chem. Soc. 2014, 136 (21), 7734-7739.

(5) Strasser, P.; Koh, S.; Anniyev, T.; Greeley, J.; More, K.; Yu, C.; Liu, Z.; Kaya, S.; Nordlund, D.; Ogasawara, H.; Toney, M. F.; Nilsson, A. Lattice-Strain Control of the Activity in Dealloyed Core-Shell Fuel Cell Catalysts. Nat. Chem. 2010, 2 (6), 454460.

(6) Luo, M.; Guo, S. Strain-Controlled Electrocatalysis on Multimetallic Nanomaterials. Nat. Rev. Mater. 2017, 2 (11), 17059.

Bu, L.; Zhang, N.; Guo, S.; Zhang, X.; Li, J.; Yao, J.; Wu, T.; Lu, G.; Ma, J.-Y.; Su, D.; Huang, X. Biaxially Strained PtPb/Pt Core/Shell Nanoplate Boosts Oxygen Reduction Catalysis. Science (80-. ). 2016, 354 (6318), 1410-1414.

(8) Li, M.; Zhao, Z.; Cheng, T.; Fortunelli, A.; Chen, C.-Y.; Yu, R.; Zhang, Q.; Gu, L.; Merinov, B. V.; Lin, Z.; Zhu, E.; Yu, T.; Jia, Q.; Guo, J.; Zhang, L.; Goddard III, W. A.; Hunag, Y.; Duan, X. Ultrafine Jagged Platinum Nanowires Enable Ultrahigh Mass Activity for the Oxygen Reduction Reaction. Science (80-. ). 2016, 354 (6318), 1414-1419.

Chen, C.; Kang, Y.; Huo, Z.; Zhu, Z.; Huang, W.; Xin, H. L.; Snyder, J. D.; Li, D.; Herron, J. A.; Mavrikakis, M.; Chi, M.; More, K. L.; Li, Y.; Markovic, N. M.; Somorjai, G. A.; Yang, P.; Stamenkovic, V. R. .Highly Crystalline Multimetallic Nanoframes with Three-Dimensional Electrocatalytic Surfaces. Science (80-. ). 2014, 343 (6177), 1339-1343.

Benedetti, T. M.; Andronescu, C.; Cheong, S.; Wilde, P.; Kientz, M.; Tilley, R. D.; Schuhmann, W.; Gooding, J. J. Electrocatalytic Nanoparticles That Mimic the Three Dimensional Geometric Architecture of Enzymes: Nanozymes. Angew. Chem. - Int. Ed. 2018, 140 (41), 13449-13455.

Zhang, Z.; Liu, G.; Cui, X.; Chen, B.; Zhu, Y.; Gong, Y.; Saleem, F.; Xi, S.; Du, Y.; Borgna, A.; Lai, Z.; Zhang, Q.; Li, B.; Zong, Y.; Han, Y.; Gu, L.; Zhang, H.. Crystal Phase and Architecture Engineering of Lotus-Thalamus-Shaped Pt-Ni Anisotropic Superstructures for Highly Efficient Electrochemical Hydrogen Evolution. Adv. Mater. 2018, 30 (30), 1801741.

Subbaraman, R.; Tripkovic, D.; Strmcnik, D.; Chang, K.-C.; Uchimura, M.; Paulikas, A. P.; Stamenkovic, V.; Markovic, N. M. Enhancing Hydrogen Evolution Activity in Water Splitting by Tailoring $\mathrm{Li}^{+}-\mathrm{Ni}(\mathrm{OH})_{2}$-Pt Interfaces. Science (80-. ). 2011, 334 (6060), 1256-1260.

Feng, X.; Wang, H.; Bo, X.; Guo, L. Bimetal-Organic Framework-Derived Porous Rodlike Cobalt/Nickel Nitride for All-pH Value Electrochemical Hydrogen Evolution. ACS Appl. Mater. Interfaces 2019, 11 (8), 8018-8024.

Wang, P.; Zhang, X.; Zhang, J.; Wan, S.; Guo, S.; Lu, G.; Yao, J.; Huang, X. Precise Tuning in Platinum-Nickel/Nickel Sulfide Interface Nanowires for Synergistic Hydrogen Evolution Catalysis. Nat. Commun. 2017, 8 (1), 14580.

Cao, Z.; Chen, Q.; Zhang, J.; Li, H.; Jiang, Y.; Shen, S.; Fu, G.; Lu, B.; Xie, Z.; Zheng, L. Platinum-Nickel Alloy Excavated NanoMultipods with Hexagonal Close-Packed Structure and Superior Activity towards Hydrogen Evolution Reaction. Nat. Commun. 2017, 8, 15131.

(16) Wang, P.; Jiang, K.; Wang, G.; Yao, J.; Huang, X. Phase and Interface Engineering of Platinum-Nickel Nanowires for Efficient Electrochemical Hydrogen Evolution. Angew. Chem. - Int. Ed. 2016, 55 (41), 12859-12863.

Liu, E.; Li, J.; Jiao, L.; Doan, H. T. T.; Liu, Z.; Zhao, Z.; Huang, Y.; Abraham, K. M.; Mukerjee, S.; Jia, Q. Unifying the Hydrogen 
Evolution and Oxidation Reactions Kinetics in Base by Identifying the Catalytic Roles of Hydroxyl-Water-Cation Adducts. J. Am. Chem. Soc. 2019, 141 (7), 3232-3239.

(18) Li, Z.; Yu, C.; Wen, Y.; Gao, Y.; Xing, X.; Wei, Z.; Sun, H.; Zhang, Y. W.; Song, W. Mesoporous Hollow Cu-Ni Alloy Nanocage from Core-Shell Cu@Ni Nanocube for Efficient Hydrogen Evolution Reaction. ACS Catal. 2019, 9 (6), 5084-5095.

(19) Lentijo-Mozo, S.; Tan, R. P.; Garcia-Marcelot, C.; Altantzis, T.; Fazzini, P.-F.; Hungria, T.; Cormary, B.; Gallagher, J. R.; Miller, J. T.; Martinez, H.; Schrittwieser, S.; Schotter, J.; Respaud, M.; Bals, S.; van Tendeloo, G.; Gatel, C.; Soulantica, K. Air- and Water-Resistant Noble Metal Coated Ferromagnetic Cobalt Nanorods. ACS Nano 2015, 9 (3), 2792-2804.

(20) Niu, Z.; Becknell, N.; Yu, Y.; Kim, D.; Chen, C.; Kornienko, N.; Somorjai, G. A.; Yang, P. Anisotropic Phase Segregation and Migration of Pt in Nanocrystals En Route to Nanoframe Catalysts. Nat. Mater. 2016, 15 (11), 1188-1194.

(21) Zhang, S.; Hao, Y.; Su, D.; Doan-Nguyen, V. V. T.; Wu, Y.; Li, J.; Sun, S.; Murray, C. B. Monodisperse Core/Shell Ni/FePt Nanoparticles and Their Conversion to Ni/Pt to Catalyze Oxygen Reduction. J. Am. Chem. Soc. 2014, 136 (45), 3-11.

(22) Liu, H.; Ma, X.; Hu, H.; Pan, Y.; Zhao, W.; Liu, J.; Zhao, X.; Wang, J.; Yang, Z.; Zhao, Q.; Ning, H.; Wu, M. Robust NiCoP/CoP Heterostructures for Highly Efficient Hydrogen Evolution Electrocatalysis in Alkaline Solution. ACS Appl. Mater. Interfaces 2019, 11 (17), 15528-15536.

(23) Gloag, L.; Benedetti, T. M.; Cheong, S.; Li, Y.; Chan, X.-H.; Lacroix, L.-M.; Chang, S. L. Y.; Arenal, R.; Florea, I.; Barron, H.; Barnard, A. S.; Henning, A. M.; Zhao, C.; Schuhmann, W.; Gooding, J. J.; Tilley, R. D. Three-Dimensional Branched and Faceted Gold-Ruthenium Nanoparticles: Using Nanostructure to Improve Stability in Oxygen Evolution Electrocatalysis. Angew. Chem. - Int. Ed. 2018, 57 (32), 10241-10245.

(24) Gloag, L.; Benedetti, T. M.; Cheong, S.; Marjo, C. E.; Gooding, J. J.; Tilley, R. D. Cubic-Core Hexagonal-Branch Mechanism to Synthesize Bimetallic Branched and Faceted Pd-Ru Nanoparticles for Oxygen Evolution Reaction Electrocatalysis. J. Am. Chem. Soc. 2018, 140 (40), 12760-

(25) Gloag, L.; Benedetti, T. M.; Cheong, S.; Webster, R. F.; Marjo, C. E.; Gooding, J. J.; Tilley, R. D. Pd-Ru Core-Shell Nanoparticles with Tunable Shell Thickness for Active and Stable Oxygen Evolution Performance. Nanoscale 2018. 10 (32), 15173-15177.

(26) Poerwoprajitno, A. P.; Gloag, L.; Benedetti, T. M.; Cheong, S.; Watt, J.; Huber, D. L.; Gooding, J. J.; Tilley, R. D. Formation of Branched Ruthenium Nanoparticles for Improved Electrocatalysis of Oxygen Evolution Reaction. Small 2018, 15 (17), 1804577

(27) LaGrow, A. P.; Cheong, S.; Watt, J.; Ingham, B.; Toney, M. F.; Jefferson, D. A.; Tilley, R. D. Can Polymorphism Be Used to Form Branched Metal Nanostructures? Adv. Mater. 2013, 25 (11), 1552-1556.

(28) Poerwoprajitno, A. R.; Gloag, L.; Cheong, S.; Gooding, J. J.; Tilley, R. D. Synthesis of Low- and High-Index Faceted Metal (Pt, Pd, Ru, Ir, Rh) Nanoparticles for Improved Activity and Stability in Electrocatalysis. Nanoscale 2019.

(29) Chen, Z.-J.; Cao, G.-X.; Gan, L.-Y.; Dai, H.; Xu, N.; Zang, M.-J.; Dai, H.-B.; Wu, H.; Wang, P. Highly Dispersed Platinum on Honeycomb-like NiO@Ni Film as a Synergistic Electrocatalyst for the Hydrogen Evolution Reaction. ACS Catal. 2018, 8 (9), 8866-8872.

(30) Kim, Y.-G.; Kim, J. Y.; Vairavapandian, D.; Stickney, J. L. Platinum Nanofilm Formation by EC-ALE via Redox Replacement of UPD Copper: Studies Using in-Situ Scanning Tunneling Microscopy. J. Phys. Chem. B 2006, 110 (36), 17998-18006.

(31) Wang, Y.; Chen, L.; Yu, X.; Wang, Y.; Zheng, G. Superb Alkaline Hydrogen Evolution and Simultaneous Electricity Generation by Pt-Decorated $\mathrm{Ni}_{3} \mathrm{~N}$ Nanosheets. Adv. Energy Mater. 2017, 7 (2), 1601390.

(32) Cheng, N.; Stambula, S.; Wang, D.; Banis, M. N.; Liu, J.; Riese, A.; Xiao, B.; Li, R.; Sham, T.-K.; Liu, L.-M.; Botton, G. A.; Sun, X. Platinum Single-Atom and Cluster Catalysis of the Hydrogen Evolution Reaction. Nat. Commun. 2016, 7 (1), 13638. 6430. 9050
Xing, Z.; Han, C.; Wang, D.; Li, Q.; Yang, X. Ultrafine Pt Nanoparticle-Decorated $\mathrm{Co}(\mathrm{OH})_{2}$ Nanosheet Arrays with Enhanced Catalytic Activity toward Hydrogen Evolution. ACS Catal. 2017, 7 (10), 7131-7135.

Straney, P. J.; Marbella, L. E.; Andolina, C. M.; Nuhfer, N. T.; Millstone, J. E. Decoupling Mechanisms of Platinum Deposition on Colloidal Gold Nanoparticle Substrates. J. Am. Chem. Soc. 2014, 136 (22), 7873-7876.

Yin, H.; Zhao, S.; Zhao, K.; Muqsit, A.; Tang, H.; Chang, L.; Zhao, H.; Gao, Y.; Tang, Z. Ultrathin Platinum Nanowires Grown on Single-Layered Nickel Hydroxide with High Hydrogen Evolution Activity. Nat. Commun. 2015, 6 (1),

Zhao, Z.; Liu, H.; Gao, W.; Xue, W.; Liu, Z.; Huang, J.; Pan, X.; Huang, Y. Surface-Engineered PtNi-O Nanostructure with Record-High Performance for Electrocatalytic Hydrogen Evolution Reaction. J. Am. Chem. Soc. 2018, 140 (29), 9046-

Zhang, L.; Han, L.; Liu, H.; Liu, X.; Luo, J Potential-Cycling Synthesis of Single Platinum Atoms for Efficient Hydrogen Evolution in Neutral Media Angew. Chem. - Int. Ed.. 2017, 56 (44) 13694-13698.

Elbert, K.; Hu, J.; Ma, Z.; Zhang, Y.; Chen, G.; An, W.; Liu, P. Isaacs, H. S.; Adzic, R. R.; Wang, J. X. Elucidating Hydrogen Oxidation / Evolution Kinetics in Base and Acid by Enhanced Activities at the Optimized Pt Shell Thickness on the $\mathrm{Ru}$ Core. 2015, 5 (11), 6764-6772

Durst, J.; Siebel, A.; Simon, C.; Hasché, F.; Herranz, J.; Gasteiger, H. A. New Insights into the Electrochemical Hydrogen Oxidation and Evolution Reaction Mechanism. Energy Environ. Sci. 2014, 7 (7), 2255-2260.

Yu, X.; Yu, Z. Y.; Zhang, X. L.; Zheng, Y. R.; Duan, Y.; Gao, Q.; Wu, R.; Sun, B.; Gao, M. R.; Wang, G.; Yu, S. H. "Superaerophobic" Nickel Phosphide Nanoarray Catalyst for Efficient Hydrogen Evolution at Ultrahigh Current Densities. J. Am. Chem. Soc. 2019, 141 (18), 7537-7543.

Kwon, S. G.; Krylova, G.; Phillips, P. J.; Klie, R. F.; Chattopadhyay, S.; Shibata, T.; Bunel, E. E.; Liu, Y.; Prakapenka, V. B.; Lee, B.; Shevchenko, E. V. Heterogeneous Nucleation and Shape Transformation of Multicomponent Metallic Nanostructures. Nat. Mater. 2015, 14 (2), 215-223. Chattot, R.; Le Bacq, O.; Beermann, V.; Kühl, S.; Herranz, J.; Henning, S.; Kühn, L.; Asset, T.; Guétaz, L.; Renou, G.; Drnec, J.; Bordet, P.; Pasturel, A.; Eychmüller, A.; Schmidt, T. J.; Strasser, P.; Dubau, L.; Maillard, F. Surface Distortion as a Unifying Concept and Descriptor in Oxygen Reduction Reaction Electrocatalysis. Nat. Mater. 2018, 17 (9), 827-833. Luo, M.; Sun, Y.; Zhang, X.; Qin, Y.; Li, M.; Li, Y.; Li, C.; Yang, Y.; Wang, L.; Gao, P.; Lu, G.; Guo, S. Stable High-Index Faceted Pt Skin on Zigzag-Like PtFe Nanowires Enhances Oxygen Reduction Catalysis. Adv. Mater. 2018, 30 (10), 1705515.

Calle-Vallejo, F.; Tymoczko, J.; Colic, V.; Vu, Q. H.; Pohl, M. D.; Morgenstern, K.; Loffreda, D.; Sautet, P.; Schuhmann, W.; Bandarenka, A. S. Finding Optimal Surface Sites on Heterogeneous Catalysts by Counting Nearest Neighbors. Science (80-. ). 2015, 350 (6257), 185-189.

Yang, J.; Yang, J.; Ying, J. Y. Morphology and Lateral Strain Control of Pt Nanoparticles via Core-Shell Construction Using Alloy AgPd Core Toward Oxygen Reduction Reaction. ACS Nano 2012, 6 (11), 9373-9382.

Sneed, B. T.; Brodsky, C. N.; Kuo, C.-H.; Lamontagne, L. K.; Jiang, Y.; Wang, Y.; Tao, F.; Huang, W.; Tsung, C.-K Nanoscale-Phase-Separated Pd-Rh Boxes Synthesized via Metal Migration: An Archetype for Studying Lattice Strain and Composition Effects in Electrocatalysis. J. Am. Chem. Soc. 2013, 135 (39), 14691-14700.

Lu, S.; Zhuang, Z. Investigating the Influences of the Adsorbed Species on Catalytic Activity for Hydrogen Oxidation Reaction in Alkaline Electrolyte. J. Am. Chem. Soc. 2017, 139 (14), 5156-5163.

Sheng, W.; Zhuang, Z.; Gao, M.; Zheng, J.; Chen, J. G.; Yan, Y. Correlating Hydrogen Oxidation and Evolution Activity on Platinum at Different $\mathrm{pH}$ with Measured Hydrogen Binding Energy. Nat. Commun. 2015, 6 (1), 5848. 


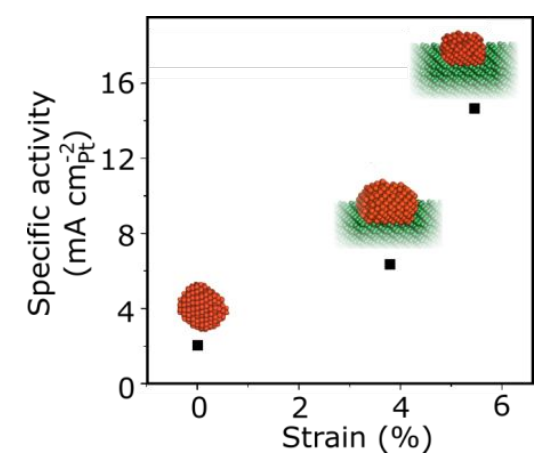

